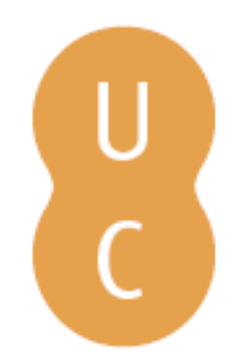

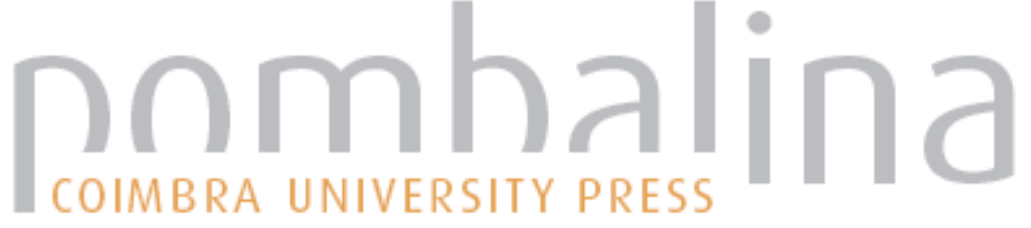

\section{Alberti e Filarete: da perspetiva à cidade ideal}

Autor(es): $\quad$ Murtinho, Vitor

Publicado por: Imprensa da Universidade de Coimbra

URL persistente:

URI:http://hdl.handle.net/10316.2/36674

DOI:

DOI:http://dx.doi.org/10.14195/978-989-26-1015-3_12

Accessed : $\quad$ 26-Apr-2023 13:11:39

A navegação consulta e descarregamento dos títulos inseridos nas Bibliotecas Digitais UC Digitalis, UC Pombalina e UC Impactum, pressupõem a aceitação plena e sem reservas dos Termos e Condições de Uso destas Bibliotecas Digitais, disponíveis em https://digitalis.uc.pt/pt-pt/termos.

Conforme exposto nos referidos Termos e Condições de Uso, o descarregamento de títulos de acesso restrito requer uma licença válida de autorização devendo o utilizador aceder ao(s) documento(s) a partir de um endereço de IP da instituição detentora da supramencionada licença.

Ao utilizador é apenas permitido o descarregamento para uso pessoal, pelo que o emprego do(s) título(s) descarregado(s) para outro fim, designadamente comercial, carece de autorização do respetivo autor ou editor da obra.

Na medida em que todas as obras da UC Digitalis se encontram protegidas pelo Código do Direito de Autor e Direitos Conexos e demais legislação aplicável, toda a cópia, parcial ou total, deste documento, nos casos em que é legalmente admitida, deverá conter ou fazer-se acompanhar por este aviso. 
IMPRENSA DA

UNIVERSIDADE

DE COIMBRA

COIMBRA

UNIVERSITY

PRESS

\section{NA GÉNESE DAS RACIONALIDADES MODERNAS II}

Em torno de Alberti e do Humanismo

MÁRIO KRÜGER et alii

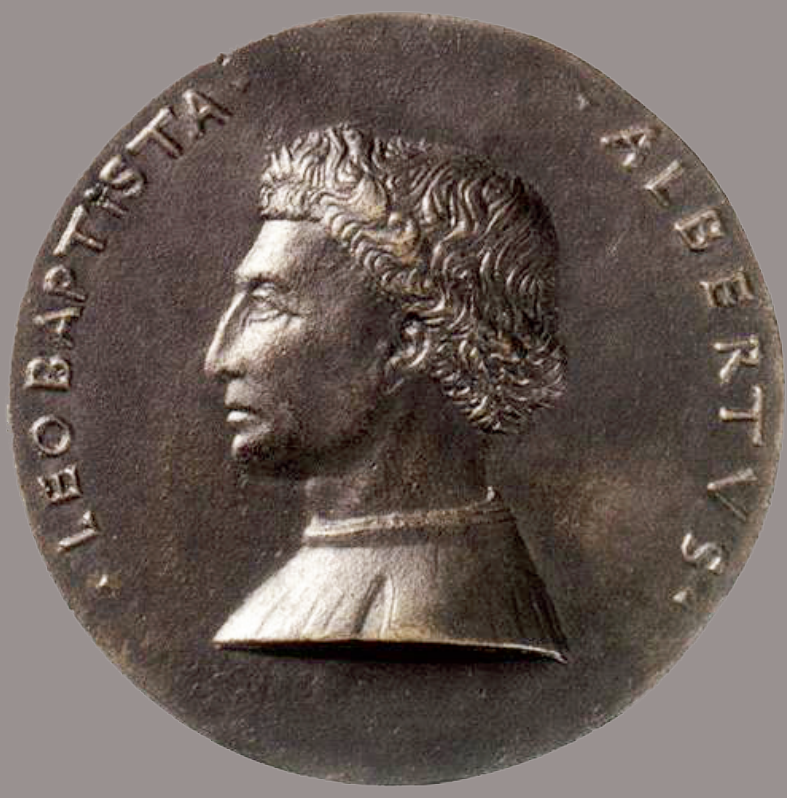


ALB ERTI E FILARETE:

DA PERSPETIVA À CIDADE IDEAL

Vitor Murtinho

\section{Resumo}

Leon Battista Alberti e Antonio Averlino (conhecido como Filarete) são, inexoravelmente dois importantes personagens renascentistas. Com capacidades multifacetadas, distinguiram-se na prática da arquitetura, tendo para o efeito ambos escrito um tratado sobre esta disciplina. Apesar de terem percursos profissionais e pessoais bem distintos, é possível encontrar, também, inúmeras similitudes. Neste campo é de referir os interesses pelo desenho e pela perspetiva. Este artigo pretende fazer o confronto entre as competências, virtudes e percursos destes destacados homens renascentistas.

Alberti; Filarete; Arquitetura; Biografia

\section{Résumé}

Leon Battista Alberti et Antonio Averlino - connu sous le nom de Filarete - sont inexorablement deux personnages importants de la Renaissance. Avec des capacités polyvalentes, les deux se sont distingués dans la pratique de l'architecture et, à cette fin, ils ont écrit un traité sur ce sujet. Bien qu'ils aient très différents parcours professionnels et personnels, nous pouvons également trouver de nombreuses similitudes. Dans ce domaine, il convient de noter l'intérêt par le dessin et par la perspective. Cet article vise à la 
confrontation entre les compétences, les vertus et les routes de ces illustres hommes de la Renaissance.

Alberti; Filarete; Architecture; Biographie

\begin{abstract}
Leon Battista Alberti and Antonio Averlino di Pietro Averlino (known as Filarete, from the Greek for lover of excellence) are, inexorably, two important renaissance personalities. With multifaceted capabilities, both distinguished themselves in the practice of architecture, and to this end both written a treatise on this subject. Although they have very different professional and personal paths, its possible to find also many similarities. In this field it should be noted the interest by drawing and of geometric perspective. This article aims at the confrontation between the skills, virtues, and routes of these outstanding Renaissance men.
\end{abstract}

Alberti; Filarete; Architecture; Biography 
Battista Alberti e Antonio Averlino são inquestionavelmente dois importantes personagens que, cada um à sua maneira, marcaram indelevelmente o pensamento ainda no século que os viu nascer, como cumulativamente em períodos posteriores. ${ }^{321}$ Todavia não constitui um propósito aqui colocar num mesmo patamar personalidades tão diferentes, com produções que divergem quantitativa e qualitativamente. Por esse facto, o que se pretende é encontrar pontos de toque, similitudes e pontos de convergência, num processo determinante que tem o seu principal desenvolvimento em pleno século XV.

No caso, não se conhece na extensa obra escrita de Leon Battista Alberti, nenhuma referência ou algum dado que permita descortinar alguma influência de Antonio Averlino. ${ }^{322}$ No entanto são profícuas e notórias as influências, diretas ou indiretas, que Battista Alberti teve sobre Averlino, designadamente naquilo que configura as suas fontes escritas. Paralelamente, conhecendo as biografias e as especificidades de cada um destes renascentistas é possível encontrar algumas semelhanças que os podem aproximar nalgumas particularidades. Ambos ensaiaram a arte da escrita, Alberti de modo desmedido, quase roçando o sobre-humano, Filarete de modo mais modesto, ficando pela produção efetiva e segura de uma única publicação. Na realidade, a diversidade da obra literária albertiana - segundo Francesco Furlan - pode ser dividida, genericamente, em três tipos, identificados segundo a forma de escrita, designadamente, o tratado, o diálogo e o lúdico. ${ }^{323} \mathrm{Em}$ rigor, este enquadramento estabelece três grandes grupos ou eixos, que complementarmente abarcam a diversidade do trabalho de aquisição de conhecimento, seja ele formulado segundo metodologia construtiva ou reativa. Assim, se no caso do tratado,

321 Battista Alberti, natural de Génova, nasceu em 1404 e faleceu em 1472 em Roma; Antonio Averlino, natural de Florença, deverá ter nascido em 1400 e admissivelmente falecido em Roma por volta de 1469.

322 Mais conhecido por Filarete.

323 Esta catalogação é aquela que, em nossa opinião, melhor estabelece a tipificação da obra de Alberti e foi proposta por uma das pessoas que na atualidade melhor conhece os seus escritos e que tem dedicado a maior parte da sua investigação precisamente a esse estudo e interpretação (ver, por exemplo, FRANCESCO FURLAN, Studia Albertiana. Lectures et lecteurs de LEON BATTISTA ALBERTI, Vrin, Paris, 2003, pp.7 e seg.). 
este se debruça sobre questões relacionadas com o mundo sensível e o diálogo com o mundo das ideias e das experiências, o lúdico enfatiza o lado mais obscuro dos dois mundos referidos colocando em questão a validade científica e dando destaque às sensações e opiniões. ${ }^{324}$

Efetivamente Filarete limitou os seus escritos, pelo menos naquilo que historicamente se conhece, ao seu texto basilar designado pelo próprio de libro de architetttura e publicado sob o título Trattato di Architettura. 325 Porém, no próprio texto filaretiano é referida a existência de uma outra sua publicação, ou pelo menos do início da sua escrita, em duas circunstâncias diferentes, versando o assunto da agricultura. ${ }^{326}$ Concretamente e no contexto desta afirmação, no livro XXI do Trattato é acrescentado ainda a consulta suplementar, caso o leitor queira adquirir mais amplos conhecimentos, a leitura do texto enciclopédico História Natural de Plínio o Velho. 327

Tendo, biograficamente, Alberti e Filarete nascido e morrido em anos muito próximos, faz com que, plausivelmente, no seu período de vida tenham certamente pisado os mesmos solos ou servido um mesmo mecenas. Uma dessas coincidências é indubitavelmente o serviço ao Papa Eugénio IV $^{328}$, já que Alberti integrou por muitos anos a corte papal e Filarete concebeu e coordenou a execução das portas principais da antiga Basílica de S. Pedro em Roma, empreendimento que mobilizou os seus esforços entre 1431 e 1445.329 Por fatalidade de Filarete, estando

324 Ibidem

325 Não existem dados seguros sobre o período exato de escrita do trattato, no entanto as opiniões têm convergido para o intervalo entre 1460 a 1464 ou mesmo até 1465 . A melhor fonte sobre esta problemática continua a ser JOHN R. SPENCER, "La datazione del trattato del Filarete desunta dal suo esame interno", Rivista d'Arte, vol XXXI, 1956.

326 FILARETE, Trattato di Architettura, edição de Anna Maria Finoli e Liliana Grassi, Edizioni il Polifilo, Milão, 1972, Libro XXI, p. 637 e Libro XXIV, p. 682.

327 Apesar desta referência explícita é provável que Averlino tenha ainda em mente o De re rustica de Marco Terêncio Varrão (séc. I a. C.), mas também o livro com o mesmo nome de Lucius Junius Moderatus, conhecido como Columella (séc. I), ou então o Opus agriculturae de Ruttilio Tauro Emiliano Palladio (sec. IV), entre muitos outros.

328 Foi Papa entre 3 de março de 1431 a 23 de fevereiro de 1447.

329 Provavelmente devido ao facto de ter colaborado com Ghiberti na segunda porta do Batistério de Florença, e segundo consta ter conhecimentos sólidos na fundição de peças em metal com grandes dimensões, Filarete terá sido convidado por Eugénio IV a 
ele a laborar em Roma, em 1447, foi acusado do roubo da relíquia da cabeça de S. João Batista, motivo que provocou a sua prisão e tortura. Segundo consta, esta acusação era motivada pela rivalidade e inveja de alguns colegas de profissão, que aproveitando a morte do papa seu protetor, tiveram oportunidade para consumar um eventual desejo de vingança. Felizmente o novo papa, Nicolau V, optou por facilitar a sua libertação sem que Filarete, estranhamente, tivesse que restituir a relíquia em falta. 330 Curiosamente o cognome de Filarete, que designa em grego algo do género amante da virtude, pode estar relacionado com uma tentativa psicológica de reabilitação da sua imagem após este triste e fatal incidente que manchou a sua idoneidade e honestidade. E, se Antonio Averlino adotou o epíteto de Filarete, Alberti, talvez tentando denotar a sua capacidade empreendedora, opta por autodenominar-se como Leon que surge imediatamente antes do nome de batismo de Battista Alberti, enfatizando eventualmente a coragem que lhe foi necessária em momentos mais difíceis da sua vida.

Não consta que Alberti enquanto homem maduro tenha tido algum constrangimento análogo ao de Filarete. Todavia, também este primeiro, em período que se estendeu até idade adulta, se viu privado de pisar solos paternos devido a exílio forçado desta ala da sua família. De facto,

desenvolver a conceção e posterior execução das portas centrais da Basílica Vaticana. Essa construção viria posteriormente a ser demolida pelo papa seguinte, Nicolau $\mathrm{V}$, depois das comemorações do Jubileu de 1450 . Sobre o mesmo local foi construída a nova basílica cujo primeiro projeto era de Bernardo Rossellino, discípulo e amigo de Leon Battista Alberti. Esta importante igreja teve sucessivos projetos e intervenções de importantes arquitetos, entre eles, Giuliano da Sangallo, Bramante, Rafael Sanzio, Baldassare Peruzzi, Antonio de Sangallo, Miguel Ângelo, Vignola, Carlo Maderno, entre outros. Todavia, foi já com Carlo Maderno e no papado de Paulo V, no início do séc. XVII que este último decidiu a reposição das portas filaretianas na entrada principal, obrigando a um acrescento da altura destas. Sobre a história da Basílica de S. Pedro e concretamente das portas centrais de bronze elaboradas por Filarete ver ANGELA CIANFARINI, Luoghi Vaticani, Libreria Editrice Vaticana, Roma, 2002, principalmente capítulos IV e VI.

330 Segundo parece, o trabalho que Filarete estava a levar a cabo correspondia ao mausoléu em memória do Cardeal de Portugal, Antão Martins de Chaves na Igreja de São João de Latrão. Este terá falecido em Roma em 11 de julho de 1447 e dado a incompletude do trabalho, terá mais tarde, em 7 de fevereiro 1449, a Senhoria de Florença solicitado que Antonio Averlino pudesse entrar de novo na cidade eterna com o objetivo de terminar a tarefa iniciada e assim poder honrar os seus compromissos (consultar EUGÈNE MUNTZ, "Les mésaventures du sculpteur-architecte Filarete 1448-1449”, Courrier de l'Art, n 3, 1883, p. 33). 
as circunstâncias políticas que provocaram o desterro da sua linhagem paterna de Florença, desde os finais do século anterior (1387), motivaram o nascimento de Battista em solos diferentes dos paternos, fruto ainda de uma relação não legalizada à luz dos preceitos da época entre Lorenzo di Benedetto Alberti e a viúva Bianca Fieschi. 331 No caso de Filarete, o afastamento deste relativo à cidade de Roma foi assunto superado com o ingresso ao serviço de Francesco Sforza, em Milão, onde em 1451 surge já com responsabilidades acrescidas na reconstrução do castelo da cidade que se encontra em profunda remodelação para albergar condignamente e com segurança a família do então recentemente proclamado duque.

Verificada a influência direcionada no exclusivo sentido de Alberti sobre Filarete, impõe-se a consolidação e definição das fontes e da averiguação efetiva dos pontos de contato. $\mathrm{Na}$ realidade, conhecendo os desempenhos de cada uma destas individualidades, as afinidades encontram-se mais circunscritas ao campo das artes em geral e da arquitetura em particular. Com efeito, estas duas personalidades partilham um gosto pelas artes em geral e em particularidade a eleição da arquitetura enquanto arte maior ou expoente máximo do processo intelectual que permite as criações mais primorosas. Em rigor, as suas laborações arquitetónicas foram precedidas por intenso trabalho ou especulação em torno da arte da pintura ou da

331 As dificuldades de subsistência de Alberti são motivadas por uma sucessão de acontecimentos que levaram a uma alteração substancial do seu meio e estrutura familiar no início da sua juventude. A sua mãe faleceu em 1406, tendo o seu pai, passados dois anos, contraído matrimónio com Margherita Benini, do qual não resultaria nenhum descendente. Acontece que não tendo Lorenzo Benedetto legalizado a relação anterior, quer Battista, quer o seu irmão Carlo (nascido em 1403) ficaram condenados à situação de ilegítimos. Obviamente que com o seu pai vivo, não havia problemas de subsistência, já que esta era assegurada por este, contudo após o seu falecimento em maio de 1421 a sua realidade estava prestes a degradar-se. Se num primeiro momento, o seu tio Ricciardo se assumiu como tutor dos órfãos, após o seu falecimento no ano seguinte ao do seu progenitor a sua situação financeira viria a agravar-se, devido ao não-reconhecimento dos seus direitos hereditários. E, se o desterro dos Alberti relativamente a Florença seria definitivamente sanado com a interferência do papa Martinho V em 1428, Leon Battista só veria o seu defeito de ilegitimidade resolvido aquando da implementação de uma bula papal para efeitos de absolvição por Eugénio IV e pela sua nomeação como reitor em 1432 tendo em vista o benefício eclesiástico no priorado de San Martino a Gagalandi (Lastra a Signa) pertencente à diocese de Florença. Sobre a biografia mais detalhada da sua vida, ver a entrada de CECIL GRAYSON, "Leon Battista Alberti" in Dizionario biografico degli italiani, volume 1, Roma, 1960, pp. 702-9; e, de modo mais desenvolvido, GIROLAMO MANCINI, Vita di Leon Battista Alberti, seconda edizione completamente rinnovata com figure illustrative, Bardi Editore, Roma, 1967. 
escultura. Se no caso de Filarete são fidedignos os seus antecedentes no âmbito da escultura, no caso de Alberti, este conhecimento é somente confirmado através de processo de escrita, com textos importantes e basilares sobre metodologia e prática conceptual.

Tanto um como outro se apresentaram como indivíduos habilitados para o estudo e desenvolvimentos de construções que pretendiam satisfazer determinadas necessidades. Para esse exclusivo efeito, quer Averlino, quer Battista se assumiram como arquitetos, enaltecendo, cada um à sua maneira, a arquitetura que haviam herdado dos tempos romanos e que um estilo mais bárbaro impedia, nalguns círculos, de emergir. A autoridade de Alberti, no domínio do projeto de arquitetura deveu-se sobretudo, em primeira instância, às suas investigações e inquirições cujo resultado foi o seu tratado De re aedificatoria. Após a receção deste importantíssimo texto fundador da teoria da arquitetura renascentista, foi tal o reconhecimento de Alberti enquanto sábio das questões da arte edificatória que naturalmente este aparece ligado como consultor ou como autor de um conjunto vasto de obras. Sendo difícil nalguns casos discernir qual a profundidade do trabalho por este desempenhado, a verdade é que a crítica assume como certa a participação de Alberti em destacadas obras como as fachadas do Palazzo Rucellai e de Santa Maria Novella, em Florença, de San Francesco em Rimini ou de San Sebastiano e de Sant'Andrea em Mântua. No entanto é seguro que, sendo o acompanhamento destas feito à distância ou de modo descontínuo, Alberti tinha em permanência no estaleiro da construção um arquiteto que fazia as necessárias pontes e que na rotina do quotidiano garantia o pretendido cumprimento do seu projeto. Para esse efeito, no Palazzo Rucellai colaborou Bernardo Rossellino, em Santa Maria Novella colaborou Giovanni di Bertino, no templo malatestino de Rimini colaborou Matteo de' Pasti; em San Sebastiano e em Sant'Andrea contou com o apoio decisivo de Luca Fancelli. ${ }^{332}$ Todas estas obras têm na sua génese algum contributo de Alberti, mas nenhuma delas, pelo menos no modo como chegou à atualidade, são algo que possamos

332 Cf. DOMINGOS TAVARES, Leon Battista Alberti, Teoria da Arquitetura, Dafne Editora, Porto, 2004, p. 10. 
atribuir à sua exclusiva autoria. Ou se trata de obras restringidas e meramente mais de fachada, como o caso de Santa Maria Novella, do templo malatestiano e do Palazzo Rucellai ou obras que, apesar de mais abrangentes, não apresentam definição total que permita dizer com rigor qual a solução preconizada por Leon Battista. Um desses casos é, por exemplo, qual seria a definição da escadaria e da fachada de San Sebastiano, se é que o projeto inicial não seria mesmo térreo. ${ }^{333} \mathrm{E}$, sobretudo, muitas das tarefas nalgumas das obras referidas ou a sua totalidade, terem sido feitas já após o falecimento de Alberti, dificultando, ainda mais, as análises ou a caracterização do seu efetivo contributo. 334

Por sua vez, Filarete, que sistematicamente defendia a presença do arquiteto no ambiente da obra, tem reconhecida a autoria ou participação em vários projetos milaneses, não tendo nenhum destes tido a conclusão durante o período da sua vida. No entanto, no contexto do círculo de domínio de Francesco Sforza, Averlino acabou por estar envolvido nas construções que tiveram mais importância e que marcaram o grande estaleiro deste importante ducado. Para além da já referida fugaz colaboração do Castelo de Milão, designadamente na zona da entrada principal de acesso ao castelo, concretamente na definição da alta torre quadrada e ainda no desenho de inúmeros elementos decorativos e de alguns dos frisos 335 , importa narrar os contributos dados no Duomo ou no projeto

333 Sobre a possibilidade de San Sebastiano ter um único piso Cf. ROBERT TRAVENOR, On Alberti and the Art of Building, Yale University Press, New Haven, 1998, pp. 127-147.

334 Corolário desta afirmação são, por exemplo, as obras de Santo André de Mântua, basílica que deveria albergar uma relíquia com Sangue de Cristo e cujos trabalhos foram iniciados precisamente dois meses antes da morte de Alberti e imediatamente após a demolição da antiga igreja medieval. Esta circunstância, com vicissitudes inerentes no decurso da obra fazem com que a fachada não esteja terminada antes de 1488 , e os trabalhos haveriam de se prolongar por muitos anos, correspondendo a quatro campanhas distintas com desvio dos preceitos albertianos e culminados finalmente no final do século XVIII com a cúpula de Juvarra e o restauro de Andrea Pozzo. Outro caso é a abside da Igreja de San Martino a Gagalandi cuja intervenção foi desenvolvida entre 1473 a 1476, segundo a indicação testamentária de Alberti (MASSIMO BULGARELLI, "Alberti a Mantova. Divagazioni intorno a Sant'Andrea", Annali di architettura, n ${ }^{\circ}$ 15, 2003, p. 11; EUGENE JOHNSON S. Andrea in Mantua, Pensylvania State University Press, London, 1975, pp. 8 a 42; GABRIELE MOROLLI, "Da un Brunelleschi apocrifo a un Alberti postumo" in San Martino a Gargalandi, Edifir Edizioni, Firenze, 2001, pp. 36 a 48).

335 Cf. GIANFRANCO PERTOT, "La fabbrica viscontea: sopravvivenze e integrazioni" in Il Castello Sforzesco di Milano, Skira, Milão, 2005, pp. 80 a 81. 
do Ospedale Maggiore da mesma cidade. Como admitidas intervenções filaretianas, acrescem os casos de um projeto de um arco celebrativo para Cremona e o Duomo de Bergamo (Chiesa Maggiore). Nestes últimos casos, admite-se que a solução proposta se aproxime de imagens específicas que Filarete apresenta e descreve no seu tratado. Segundo parece, no caso concreto de Bérgamo, o desenho de Filarete não é muito diferente da estrutura espacial que, pelo menos até ao século XVII, aparece como hipótese recorrente. Por outro lado, a representação averliana da vista frontal da igreja assemelha-se muito à Cappella Colleoni, situada nas imediações, cujo projeto é da autoria de Giovanni Antonio Amadeo e que foi construída durante a década de setenta do século XV. ${ }^{336} \mathrm{O}$ empreendimento mais importante que Filarete teve em mãos e que maior impacto teve em termos da história da arquitetura foi, inequivocamente, o projeto do Hospital maior de Milão, também conhecido como Ca' Granda. É seguro que o contributo averliano se resumiu muito mais à definição do modelo organizativo e concetual do que ao processo de concretização física, já que este se arrastou por período muito posterior à vida do próprio arquiteto. Porém, o desenvolvimento físico da estrutura do edifício, sob o ponto de vista organizativo e de implantação, respeita em muito o propósito filaretiano, atestando a importância que o projeto inicial terá tido em termos da consolidação da forma final do edifício construído. De facto, durante o século XV somente foi executada uma das duas cruzes gregas claustrais, correspondendo à parte situada entre as vias Festa del Perdono e S. Lazaro; o claustro central, sem igreja a meio e de largura mais reduzida, bem como a outra cruz grega somente teriam

336 No Trattato, Filarete descreve uma cidade imaginária designada como Sforzinda onde, entre outras coisas, explica com algum detalhe e ilustra o castelo do senhor e as respetivas portas. No caso da entrada do castelo, o desenho correspondente, que aparece no livro sexto, tem sido descrito como sendo uma aproximação do projeto que Filarete teria feito para o arco em Cremona (TAV. 21, f. 42r.); por sua vez, a Catedral de Bérgamo aparece representada de modo indireto quando Averlino faz uma proposta para uma igreja em memória de São Jerónimo e afirma ser esta igual à que havia projetado precisamente para Bérgamo (TAV. 95, f. 123v.). No caso do Arco de Cremona ver MICHELE LAZZARONI e ANTONIO MUNOZ, Filarete, scultore e architetto del secolo XV, Roma, Modes editore, 1908, pp. 180 a 182; sobre s Catedral de Bérgamo consultar GRAZIELLA COLMUTO ZANELLA, "L'Architettura" in Il Duomo di Bergamo, Edizioni Bolis, Bergamo, 1991, pp. 136 a 173. 
o seu início em pleno século XVII. Estas circunstâncias dão relevo ao projeto filaretiano que apesar de não estar logo totalmente evidente nas primeiras intervenções, foi um guião que condicionou substancialmente o desenho na sua evolução para a solução definitiva. 337

No campo da escrita, como já se referiu, reconhece-se fulgor desequilibrado entre Alberti e Filarete, sabendo da proficuidade do primeiro, perdendo-se nos estilos e na polivalência de conteúdos, do segundo subsiste escrita discreta e sumariamente enquadrada entre o romance, com diálogo e informação dispersa sobre inúmeros assuntos, mas mais incisivos na arte da arquitetura. Alberti inicia o seu processo de escrita como corolário de um processo formativo muito exigente e eventualmente alterna estilos e saberes consoante as solicitações ou as agruras da vida assim o determinam. Quando, em período subsequente à perda do pai, Alberti é atingido por tendências depressivas, refugia-se no estudo e desenvolvimento da matemática e das artes, provavelmente menos exigentes em termos de memória, para conjuntamente com uma prática desportiva frequente, conseguir superar tão periclitante ciclo. Se bem que o âmbito das pesquisas albertianas explodem em inúmeros temas problemáticos, uma das suas obras maiores, principalmente pelo impacto que teve no exercício posterior da arte arquitetónica é, sem sombra de dúvida, o seu De re aedificatoria. Nesta contextura, este texto constituindo uma alternativa moderna aos vitruvianos dez livros sobre arquitetura, pressupõe e dá nota de um domínio anormal dos preceitos da edificação clássica, afirmando-se como um verdadeiro tratado desta arte maior. Esta obra incorpora todo um saber recolhido pacientemente a partir de toda a bibliografia existente à época, contemporânea ou mais antiga, permitindo a construção de uma publicação que para além de possuidora de uma inegável erudição, constitui-se como um texto exemplar e simultaneamente fundacional da teoria da arquitetura.

337 Sobre a evolução do Hospital de Milão sugere-se a consulta do livro de LILIANA GRASSI, Lo 'Spedale di Milano, Storia e Restauro, Universitá degli Studi di Milano, Milão, 1972. De notar que esta arquiteta foi a autora da conversão da construção para efeitos de edifício universitário, após o tremendo impacto que sofreu durante os bombardeamentos na Segunda Guerra Mundial. 
Neste preciso domínio o De re aedificatoria apresenta uma linguagem disciplinar própria, alicerçar, fornecendo modelos conceptuais e que de certo modo prescreve o modo ou os modos de fazer boa arquitetura. No caso particular de Filarete, escreveu um livro que genericamente autodenominou como arquitetónico livro 338 e que ardilosamente podendo assemelhar-se a um tratado análogo ao de Vitrúvio ou de Alberti, corresponde a uma escrita sob a forma romanceada e que de algum modo exalta aquilo que poderá ter sido ou aquilo que este gostaria de ter sido, o seu desempenho e labuta por terras milanesas. 339

Sabe-se que nas terras lombardas devido à particularidade do clima e das características dos terrenos havia uma limitada oferta em termos de pedra, pelo que o mais comum era o recurso à construção em tijolo. Esta circunstância tinha como evidência a existência de múltiplos interesses ligados a este material, bem como localmente um enorme domínio deste sistema construtivo. Como Filarete era um arquiteto com formação classicizante e que fazia a apologia da utilização preferencial das rochas ornamentais, é particularmente manifesto que esta sua prerrogativa gerava forte contestação nos meios locais milaneses. Por outro lado, muita da pormenorização que Averlino defende em termos de execução de obra não era a mais adequada para um ambiente tão húmido como aquele que encontrou em Milão, sendo várias, por exemplo, as referências a problemas derivados a infiltrações no Hospital de Milão. Ora, estes fatos, entre outros, foram certamente explorados até à exaustão, sendo absolutamente claro, durante a sua estada na Lombardia, a incidência de uma opinião muito determinada quanto à sua

\footnotetext{
338 FILARETE, Trattato di Architettura, p. 7
}

339 Não deixa de ser curioso o facto de, quer o Trattato de Filarete, quer o De re aedificatoria de Alberti só terem sido publicados depois da sua morte. Outra questão importante tem a ver com a presença de três textos sobre arquitetura, Vitrúvio, Alberti e Filarete na biblioteca privada de Mattia Corvino (1443-1490), monarca do importante Regno di Ungheria. Como se sabe, o De re aedificatoria foi publicado pela primeira vez em 1485 numa edição ao cuidado de Angelo Poliziano. Mas, por outro lado, precisamente por encomenda de Mattia Corvino, seria elaborada pelo humanista Antonio Bonfini uma versão latina de texto filaretiano, que teria a sua conclusão precisamente na mesma década da edição albertiana. Ver ANTONIO BONFINI, La Latinizzazione del Trattato d'Architettura di Filarete, edição ao cuidado de Maria Beltramini, Scuola Normale Superiore Pisa, Pisa, 2000; consultar ainda PÉTER FARBAKY, "Il ruolo dela teoria e dela prassi dell'architettura rinascimentale nela rappresentanza del podere di Mattia Corvino", in Mattia Corvino e Firenze, Giunte Editore, Florença, 2013, pp. 118 a 125. 
competência e capacidade para gerir os diferentes estaleiros onde colaborou. No caso da região de Milão, existiam lobbies muito visíveis, quer em termos da defesa de um tipo de arquitetura ainda muito formatada nas formas góticas, quer na quase imposição de um clã de arquitetos socialmente bastante reconhecidos, cujos elementos mais destacados pertenciam à família dos Solari. ${ }^{340}$ Ora, sendo segura a dificuldade de Filarete em se conseguir impor como arquiteto ducal, principalmente entre os seus pares nativos, é percetível que naturalmente surja um processo de escrita como estratégia de afirmação da sua competência e enaltecimento do seu profundo conhecimento, principalmente nas matérias da arquitetura.

Numa época em que se assiste a uma consciente revivescência dos valores clássicos, consagrada como verdadeira tradição italiana, é corrente muitos artistas, designadamente aqueles que se dedicam às artes da esculturas, fazerem reproduções de elementos ou artefatos mais antigos, denotando o desenvolvimento por um gosto antiquário. Assim, são inúmeras as reproduções de moedas com efígies de imperadores romanos, ou então outras plaquetas $^{341}$ ou pequenas esculturas como é o caso da célebre miniatura

340 A influência da família Solari está associada à própria história do Duomo de Milão, sendo que um dos primeiros nomes a aparecer foi Marco da Carona (Carona era uma pequena vila situada junto ao logo de Lugano, atualmente pertencente à Suíça), patriarca desta dinastia, em 1389. Em 1401, no calor da celebrizada discussão sobre se o perfil da catedral deve ser ad quadratum ou ad triangulum, cujo episódio é bem descrito por Ackerman, é precisamente o nome de Marco da Carona que lidera o grupo de engenheiros lombardos que debita argumentos contra o arquiteto francês Jean Mignot, autor a esse propósito da celebrizada frase: ars sine scientia nibil est. Esta frase acutilante, provavelmente feriu o orgulho milanês e, sendo certo que Mignot desapareceu definitivamente da história do desenvolvimento construtivo do duomo, Marco continuou como responsável pelos trabalhos. Este episódio deve ter sido determinante para gerar grandes anticorpos na comunidade relativamente a arquitetos estrangeiros. Dos três filhos de Marco da Carona (Alberto, Pietro e Giovanni Solari), todos ligados a questões relacionadas com a construção ou escultura, pelo menos Giovanni apareceu ligado à Fabbrica durante a década de 1450. Seria ainda o seu filho, Guiniforte, quem em 1459 desempenha a tarefa de conduzir os trabalhos no duomo até à sua morte em 1481; foi também este quem substituiu Filarete nos trabalhos do Ospedale Maggiore de Milano após a saída deste em 1465 (ver CHARLES MORSECHECK, "The Solari Dynasty in Milan in the Fifteenth and Sixteenth Centuries, Magistri d'Europa, EdiNodo, Milão, 1996, pp. 193 a 199; JAMES ACKERMAN, "Ars Sine Scientia Nibil Est: Gothic Theory of Architecture at the Cathedral of Milan", Distance Points, Essays in Theory and Renaissance Art and Architecture, pp. 211 a 268).

341 Sobre o trabalho de Filarete em termos de placas em metal fundido, tarefa em que de algum modo este artista é especialista, sugerimos a leitura de PIETRO CANNATA, "Le Placchette del Filarete", Italian Plaquettes, National Gallery of Art, Washington, 1985, p.35 a 52; sobre a questão em geral, consultar os restantes artigos do mesmo volume. 
da estátua equestre de Marco Aurélio feita por Filarete e oferecida conjuntamente com a versão aumentada do seu Trattato di Architettura a Piero Cosimo de' Medici, pai de Lorenzo il Magnifico, aquando do seu regresso a Florença, após o abandono definitivo das terras lombardas. 342

É provavelmente nesta senda e contexto revivalista que ambos os artistas, Alberti e Filarete, elaboram ou mandam elaborar um medalhão com autorretrato numa das faces. Na outra face aparecem elementos encomiásticos que tentam enquadrar de algum modo a respetiva personalidade. A verdade é que, sendo estes dois relevos contemporâneos destes arquitetos, certamente que a sua existência é indubitavelmente um excelente veículo para o seu reconhecimento enquanto indivíduos e para a sua afirmação enquanto personalidade. De notar que na tradição romana, a representação de efígie de um imperador ou a sua reprodução em estátua era uma forma eficaz de tornar amplamente conhecida a sua imagem e obviamente a sua pessoa. Mesmo que num contexto mais restrito, a verdade é que qualquer representação gráfica ou tridimensional que permite a associação entre esta e uma pessoa determinada cumpre este desígnio, possibilitando que ela seja divulgada, apreciada e conhecida. 343 No caso de Alberti, a plaqueta apresenta no anverso a sua efígie e no reverso uma representação de olho alado. Esta última representação, tendo em vista o trabalho desenvolvido por Alberti no campo da perspetiva e conhecendo o enorme potencial que esta transporta através do desenho ou da pintura, permite especular que a sua intenção seria projetar o seu saber para domínios tão altos e tão distintos como aqueles que um olho

$342 \mathrm{O}$ monumento a Marco Aurélio antes de ir para o Campidoglio, posição que ocupa atualmente, esteve pelo menos desde a segunda metade do século VIII numa praça adjacente à Catedral de Laterano, situado no lado norte, em estreita relação com este edifício e o palácio público, o Patriarchio. Esta estátua deveria constituir em Roma um monumento com valor civil e jurídico excecional, motivo por que foi valorizado e preservado. Admissivelmente a reprodução de Filarete poderia ter sido o resultado da vontade papal de restauro ao mesmo tempo que decorriam as obras do grande portal de S. Pedro, mas talvez somente fundido quando Filarete estava já ao serviço de Francesco Sforza (sobre a história do monumento ver globalmente o livro Marco Aurélio, Storia di un monumento e del suo restauro, Silvana Editoriale, Milão, 1989; particularmente sobre o conjunto no período medieval e renascentista ver o artigo desta publicação de Lachenal, Lucilla, "Il monumento nel Medioevo fino al suo trasferimento in Campidoglio", pp. 129 a 155.

343 Cf. LUKE SYSON, "Alberti e la ritrattistica" in Leon Battista Alberti, Milão, 1994, pp. 46 a 53. 
omnipresente e omnisciente consegue congregar. Nesse âmbito, a sua visão estabelece-se como transportadora de uma visão inteligente, abrangente e sábia. Também Filarete, no anverso da sua medalha apresenta perfil rodeado por abelhas, autoproclamando-se em escrito como arquiteto e, no reverso, clarifica que tal "como o sol fornece as abelhas, assim o príncipe dá as comodidades da vida". ${ }^{34}$ Este aforismo tem subjacente a premissa da co-identificação da figura de Filarete com as abelhas, numa lógica de que este apídeo era visto como inseto trabalhador, zeloso, responsável e um notável construtor. Por outra via admite-se alguma correlação entre a feitura do medalhão e o facto de poder extrapolar-se para a circunstância de os arquitetos em geral estarem ao serviço de príncipes e, em particular, Averlino estar ao serviço de Francesco Sforza, senhor que lhe dava guarida e que de alguma forma garantia o seu sustento.

Recentrando a análise no interior da escrita arquitetónica destes dois exímios manipuladores da ciência do espaço, é imediatamente emergente a influência, para não dizer a raiz vitruviana para a estruturação e desenvolvimento do pensamento de ambos. Obviamente que esta particularidade, por si só, não constitui facto inovador pois, na contextura das artes arquitetónicas, este é um manual utilizado de modo amiúde e de faceta quase incontornável. Num período em que as reflexões sobre arquitetura não estão suficientemente maturadas e estabilizadas em torno de modelos intemporais, o percurso normal dos exímios manipuladores dos sistemas construtivos e dos programas edificatórios é tentarem encontrar alicerces em reflexões preexistentes e temporalmente validadas. Neste estrito sentido, os dez livros de arquitetura de Vitrúvio funcionam como alimento para todas estas mentes ávidas de suporte teórico e de enquadramento imagético. ${ }^{345}$ No entanto e complementarmente, ambos os tratados

344 A frase que aparece na medalha de Filarete, escrita em latim,diz o seguinte: "UT SOL AUGET APES SIC NOBIS COMODA PRINCEPS”. Cf. GUY DE TERVARENT, Attributs et symboles dans l'art profane, Droz, Geneva, 1997, pp. 19 a 20.

$345 \mathrm{O}$ recurso a fontes mais antigas é algo que está latente nos dois textos renascentistas, apesar de o ser de modo mais coerente, metódico e sustentado em Alberti. No caso de Filarete, as fontes surgem de modo mais disperso e avulso, não transparecendo um domínio tão consistente das fontes clássicas como é percetível em Alberti. Para além de Vitrúvio, é digna de nota a referência à História Natural de Plínio o Velho, mais uma vez 
renascentistas ajudam a fundar os conceitos humanistas e são determinantes para a definição do modo como a partir daí se formaliza e apresenta a arquitetura. Quer Alberti, quer Filarete fazem ampla e consciente apologia do ato de projeto enquanto laboração intelectualizada mas formalizada do edifício. Nessa esfera, aproveitando um raciocínio de Pierre Caye no caso aplicado a Alberti, mas segundo nós extensível aos dois autores, estes promovem, declaradamente, a instituição do desenho enquanto processo que se contrapõe à ideia. ${ }^{346}$ Se no caso mais tradicional, o processo de obra é ainda muito delimitado pelo decurso dos trabalhos e pela interação com as entidades promotoras, estando subjacente um princípio mais abstrato e menos palpável, norteador do destino da construção, sucessivamente flexível e adaptável, os dois textos renascentistas promovem e incentivam a laboração e discussão antecipada, induzindo a que o processo concretizador seja meramente uma etapa de uma ação prévia e totalmente controlada. De modo enfático é sobrevalorizado o todo sem detrimento das partes. Nesse domínio, tal como havia já ensaiado Vitrúvio, o par de pensadores renascentistas exaltam a necessidade de domínio dos instrumentos reguladores das formas, designadamente a geometria e o desenho. 347 Neste campo de ação, a exaltação do desenho enquanto elemento fundamental para a produção da arquitetura implementa uma dinâmica de que, de modo sistemático e abrangente, todo o processo concetual é controlado, completo e íntegro, num processo que Carlos Brandão designou como a construção do todo. 348

Também em acerto metodológico, Alberti e Filarete, para além dos instrumentos concetuais, aferidores e exploradores do espaço, propõem

em Filarete em passagem esporádica e em Alberti de modo mais organizado e com o intuito de fortalecimento de cuidada argumentação.

346 Cf. PIERRE CAYE, Empire et Décor. L'architecture et la question de la technique à l'âge humaniste et classique, Librairie Philosophique J. Vrin, Paris, 1999, pp. 48 a 50.

347 Concretamente Leon Battista Alberti, no seu De Pictura procede à sublimação declarada do processo de representação através do desenho, obviamente alicerçado em rigorosos procedimentos e conhecimentos geométricos. Já por exemplo Averlino, no Livro I diz expressamente que o arquiteto deve "saber muito de geometria e de desenho e tantas outras coisas." Consultar neste último caso, FILARETE, Trattato di Architettura, I, p. 8.

348 CARLOS ANTÔNIO LEITE BRANDÃO, Quid Tum, Editora UFMG, Belo Horizonte, 2000, p. $184 \mathrm{sgg}$. 
o recurso aos modelos físicos, normalmente lígneos, suscetíveis de fornecer informação estável e precisa. Num contexto corrente de ausência do arquiteto do estaleiro de obra, estes modelos poderiam funcionar como preciosos auxiliares em termos de progressão dos trabalhos. Obviamente que, de um modo geral, estes seriam, neste circuito, mais úteis em Alberti do que em Filarete, já que este último pugnava, por princípio, pela presença mais sistemática no estaleiro da obra. E, se curiosamente ambos aparentam ter enorme prazer nas artes do desenho, na verdade os textos albertianos são elaborados sem recurso à parte gráfica e o tratado filaretiano usa sistematicamente o desenho como complemento imagético do texto. Mas paradoxalmente os efeitos são os mesmos pois Alberti deliberadamente não recorre ao desenho, denotando enorme preocupação com a questão da reprodução do livro e se tiver um texto suficientemente detalhado e objetivo, certamente que os desenhos a partir daí produzidos terão idêntica formalização; Filarete, certamente com menos recursos discursivos, intencionalmente acrescenta o desenho como dado complementar que converge na enfatização da matéria discursiva. Neste sentido, na aparência o método seguido é supostamente difuso, mas a preocupação com o resultado é em tudo muito semelhante: rigor, precisão e objetividade. Nessa índole, de valorização do processo criativo, Filarete sublinha a importância do entendimento e da extração das medidas a partir do projeto para efeitos da construção do edifício, elementos sem os quais não se poderá concretizar este de modo conveniente. ${ }^{349}$

Se dúvidas houvesse, o que emerge como peculiar nestas três personalidades - Vitrúvio, Alberti e Filarete - é um total apego às artes de conceção e manipulação dos lugares, com uma enorme preocupação no espaço que é dentro e em redor dos edifícios, local privilegiado onde se desenvolve e desenrola a maior parte do teatro humano. Para efeitos de qualificação do construído, é imperativo o recurso sistemático ao legado romano, contagiando toda e qualquer atividade projetual ou construtiva. O crédito vitruviano é inexoravelmente algo que se impregna naturalmente no artefato construído, é algo que no caso de

349 Cf. FILARETE, Trattato di Architettura, I, p. 9. 
Filarete constitui um recurso legítimo, fundador e normativo; e, no caso de Alberti é mais um elemento histórico, é algo que presumivelmente está no seu ponto de partida mas não constitui ponto de chegada.

Curiosamente, Filarete, naquilo que genericamente pode ser referido como fonte primária no tocante à questão dos meios para a inteligibilidade do projeto na sua vertente operativa, propõe dois autores, o recorrente Vitrúvio e o contemporâneo Alberti. Porém, se expectativa houvesse que esta referência conduzisse ao expectável De re aedificatoria, o modo como é feito mais sugere e induz a um conhecimento mais aprofundado antes do De pictura e dos Elementi di pittura. ${ }^{350}$ No caso do texto Filaretiano a única circunstância em que aparentemente pode ser visado o texto sobre arquitetura de Alberti é precisamente no contexto do Libro I, onde este explicita que Battista Alberti "é entendidíssimo em geometria e em outras ciências; tendo agora feito em latim uma obra elegantíssima."351 Em toda a obra, esta é inequivocamente a única situação onde pode eventualmente ser referenciável no Trattato uma alusão ao importante texto Albertiano. Todavia, a existir, ela é suficientemente vaga e pouco conclusiva. Ainda mais, num contexto onde as referências são normalmente objetivas e concretizáveis, aquilo que se pode concluir é somente que eventualmente Filarete teria ouvido falar do De re aedificatoria, mas ter pouca noção do seu efetivo conteúdo. Dado o valor que este texto albertiano tem para a prática arquitetónica, seria praticamente impossível, se Filarete o conhe-

350 Segundo Filarete, Alberti era perito máximo na arte do desenho, a qual por sua vez constitui o fundamento das artes que são executadas através do uso da mão. Ver FILARETE, Trattato di Architettura, edição de Anna Maria Finoli e Liliana Grassi, p. 10. Noutro excerto, por exemplo, ao falar da distinção entre corpo e superfície utiliza a linguagem constante nos Elementi di pittura: "Questo cotale dispartimento del corpo e della superfice si chiama lembo, escondo che ' 1 sopradetto Battista Alberti disse ne' suoi Elementi, e questi quasi come costure d'uno panno l'asomiglia, discrimen;" (FILARETE, Trattato di Architettura, Libro XXII, p. 641). Para uma análise detalhada sobre a influência do De pictura em Filarete consultar o detalhado estudo de LUCIA BERTOLINI, "Ancora su Alberti e Filarete: per la Fortuna del De pictura Volgare", in Gli Antichi e i Moderni, Edizioni Polistampa, Tomo I, Florença, 2010, pp. 125-166.

351 "Battista Alberti, il cale a questi nostri tempi uomo dottissimo in più faculta è in questa molto perito, massime nel disegno, il quale è fondamento e via d'ogni arte che di mano si faccia, e questo lui intende otimamente, e in geometria e d'altre scienzie è intendentissimo; lui ancora ha fatto in latino opera elegantissima." FILARETE, Trattato di Architettura, I, pp. 10-11. 
cesse, limitar-se a uma referência tão genérica e abstrata. E, se o fizesse intencionalmente, seria mais razoável ignorar totalmente as referências albertianas do que fazê-lo através de outras obras que no contexto da arquitetura são inequivocamente menores quando comparadas com a dimensão teórica e de impacto do De re aedificatoria. Porém, naquilo que tem a ver com as questões da representação em perspetiva, matéria crucial quer nas artes do desenho quer da pintura, mas também artefato prospetivo em termos da arquitetura, são absolutamente claras as influências da autoridade albertiana sobre Filarete. É certo que Filarete terá estudado com minúcia o texto sobre pintura de Alberti, designadamente com mais acutilância para a escrita entre os seus livros XXII e XXIV do Trattato. Não será inocente a referência explícita ao conceito de finestra quando pretende caracterizar a superfície que suporta a representação e enquadra a cena que se pretende desenhar. ${ }^{352}$ Não obstante Filarete ser fiel aos conceitos albertianos naquilo que tem a ver com a organização do espaço dito euclidiano, no modo como formaliza a sua metodologia para concretizar a representação, esta é feita de modo original em termos literários e construtivos. No Livro I do De pictura, Alberti descreve o método para construção de uma perspetiva recorrendo a duas representações autónomas e obtendo as medidas de um desenho para outro, através de medição e transposição direta. No caso concreto de Filarete, procede-se à fusão de ambos os procedimentos, convergindo-se para um único desenho e desse modo toda a representação é feita de modo mais direto e pragmático. Esta metodologia só tem equivalência geométrica bastante posteriormente, num desenho de Leonardo da Vinci. 353 E, convenhamos, a síntese na representação é claramente uma descoberta essencial para todo o processo de laboração intelectual e de visibilidade. Em rigor e com

352 "Perché ogni cosa che l'uomo vuol fare si è mestiero di pigliare uno certo principio e forma, e com quello ordine che quela tal cosa merita seguir ela cosa proposta, sì che adunque noi prima fingeremo astare a una certa finestra, e per quela vedere tutte quelle cose le cali noi vorremo nel nostro antescritto piano discrivere e disegnare." (FILARETE, Trattato di Architettura, pp. 651 a 652).

353 A construção referida aparece no Manuscrito A, existente atualmente no Instituto de França. Sobre a costruzione legitima recomendamos a leitura de ALESSANDRO PARROCHI, "Il Filarete, Francesco di Giorgio e Leonardo sul a "costruzione legitima"”, in Rinascimento, Rivista dell'Istituto Nazionale di Studi sul Rinascimento, seconda serie, volume quinto, Sansoni Editore, Florença, 1965, pp. 155 a 167. 
rigor naquilo que tem a ver com as construções intelectualizadas através da ciência da perspetiva, o pensamento perdeu a soberania abstrata e encontrou um método eficaz e fidedigno, com reversibilidade, para tornar visível a razão e dar razão ao visível. 354

Admitindo que existiram dois caminhos distintos e autónomos, um que verteu para o De re aedificatoria e outro que verteu para o Trattato di Architettura, é óbvio que as fontes escritas, os testemunhos e os ambientes que lhes deram origem tiveram que, em muitos dos casos, ser semelhantes. Não admira, portanto, que A História Natural com o seu saber enciclopédico, de Plínio o Velho, seja um recurso partilhado por ambos os pensadores. Mas, igualmente são transversais ao pensamento e à metodologia discursiva autores como Platão e Aristóteles. ${ }^{355}$ É óbvio que a estrutura do texto filaretiano em forma de diálogo tem particulares similitudes com aquilo que constitui toda a base estrutural da filosofia platónica. Por outro lado parece plausível que na efabulação das cidades idealizadas de sforzinda e plusiapolis terá estado uma influência, mais próxima ou mais distante, tanto da política de Aristóteles como a biblioteca bistórica de Diodoro Sículo. ${ }^{356}$

Mas, se existe elemento claramente distinto do tratado filaretiano, é o facto de este propor e detalhar uma nova cidade, que batizou como sforzin$d a$, claramente em homenagem ao duque de Milão, Francesco Sforza. Esta cidade que influenciou bastante as sucessivas propostas renascentistas para cidades feitas de raiz, apresenta uma configuração exterior baseada num duplo quadrado rodado e constitui, ainda hoje, uma realização intelectual muito interessante e deveras inovadora. ${ }^{357}$ De fato, Alberti preocupou-se

354 Cf. VITOR MURTINHO, "Capítulo Quarto" de Perspetivas: O espelho maior ou o espaço do espanto, e|d|arq, Coimbra, 2000.

355 Sobre as fontes de Alberti e Filarete ver JOHN ONIONS, "Alberti and Filarete. A Study in Their Sources", Jounal of the Warburg and Courtauld Institutes, 1971, pp.96-114.

356 Parecendo mais evidente a relação com Aristóteles e Platão, será oportuna relativamente a Diodoro Sículo a consulta, por exemplo, de LILIANA GRASSI, "Sforzinda, Plusiapolis, Milano: città ideale, città del mito, città dela storia nel trattato del Filarete”, Studi di Leteratura Francese, XI, Leo Olschki Editore, 1985, p. 26 e sgg. Para perceber melhor a influência de Platão sobre Filarete recomenda-se a leitura de GIORGIA BOLDRINI, "L'umanesimo volgare del Trattato di Architettura", in Teatro e Storia, Bulzoni Editore, Roma, 2000, p. 213 a 240 , sobretudo pp. 237 a 239.

357 A descrição de sforzinda é um assunto muito transversal a quase todo o tratado filaretiano, mas a descrição da sua forma urbana aparece no final do Libro II. 
com a caracterização tipológica dos diversos edifícios que satisfaziam as necessidades correntes da época, mas quase ignorou o modo de estes se organizarem de maneira consistente. Para esse efeito são determinantes os capítulos que se referem ao ornamento de edificios sagrados e ao ornamento de edifícios profanos, respetivamente livro sétimo e livro oitavo. É muito incisiva a explicitação por parte de Alberti da caracterização de uma cidade muito orientada para as necessidades das pessoas, mas tendo como base uma reconstituição quase arqueológica de um passado glorioso mas efetivamente já distante. Por sua vez, a lógica filaretiana é a da explanação de um modelo organizacional, entremeado com laivos utópicos e adicionados a realidades distintas como a da cidade próxima de Milão ou da mais distante cidade de Veneza. ${ }^{358}$ A forma da cidade de sforzinda parece assemelhar-se à configuração imagética de Milão já que se tratava também de uma cidade rodeada por muralhas e com uma cadência quase regular de portas de entrada; por sua vez, o conjunto de canais que caracterizam a morfologia de sforzinda, podendo ser identificados com Milão, era uma característica particularmente reconhecida em Veneza.

Paralelamente, no campo das analogias, induzidas para a caracterização de determinados elementos arquitetónicos ou da própria arquitetura, ambos recorreram, de modo peculiar mas diverso a relações antropomórficas. Obviamente que nesta linha de raciocínio está a teoria vitruviana como inegável suporte. Também em cumplicidade, estes dois arquitetos, induzem a edifícios com formas reguladas e de matriz centralizada, demonstrando estarem ambos em sintonia e serem arautos daquilo que serão os novos ventos que orientarão as opções formais e espaciais. Em rigor, a adoção de pensamentos direcionados para preocupações com o bem-estar humano e a definição de palcos onde o homem enquanto sujeito produtor e intelectual é objetivamente uma figura central e tutelar, a experimentação de arquitetura com espaços centralizados, colocam particular ênfase sobre a realidade mundana e confirmam o desenvolvimento e definição de valores humanistas. Estes caminhos convergentes na definição de rumos valorativos do papel do homem no universo favorecem uma enorme liberdade de espírito e,

358 Cf. GIANNI CARLO SCIOLLA , La Città Ideale nel Rinascimento, UTET, Turim, 1975, p. 35. 
simultaneamente, provocam a alavancagem de valores que possibilitam a supressão das capacidades e o advento de rumo de progresso e de mudança.

Não constituiu propósito desta argumentação enfatizar uma óbvia diferença de estatuto que marcadamente permite distinguir estas duas eminências renascentistas. As evidências, a singularidade de inúmeras coincidências, de factos análogos e de circunstâncias aparentemente similares, potenciam e estimulam a reflexão em torno de dois caminhos que de modos diferentes, mas certamente muito valiosos, contribuíram para a consolidação de determinadas teorias e práticas da arquitetura. $\mathrm{E}$, por tudo aquilo que tenham influenciado e marcado os exercícios desta notável arte que modela e influencia o comportamento e o pensamento dos homens, é sobretudo contagiante pensar que cada um à sua escala e proporção, são ainda hoje mensageiros credíveis para a formação e consolidação das teorias e das arquiteturas mais modernas e atualizadas.

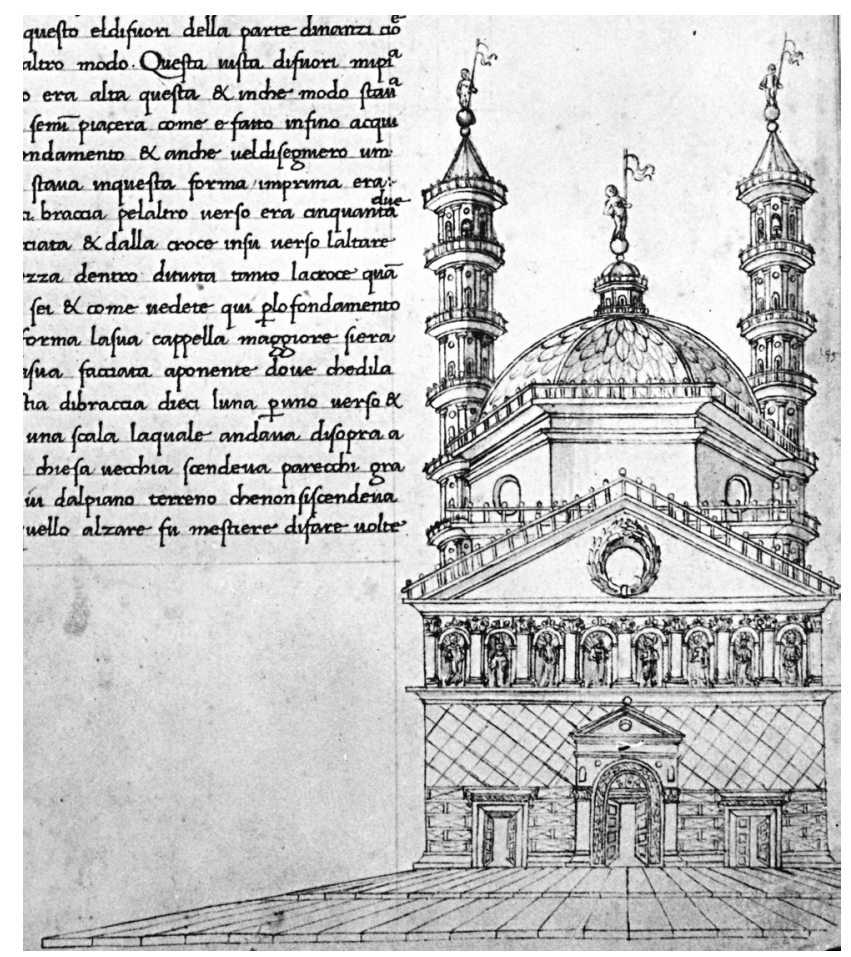

Fig. 1 - FILARETE: Codex Magliabechianus, f. 123r. Desenho da fachada da Igreja dos Eremitas de San Girolamo (Segundo Averlino, igual à de Bérgamo). 

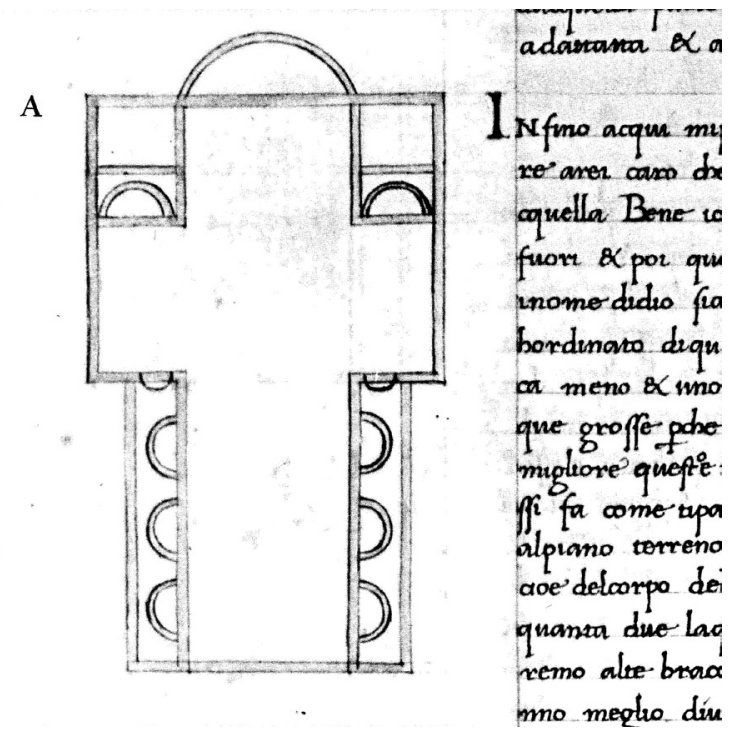

Fig. 2 - FILARETE: Codex Magliabechianus, f. 123v. Desenho da planta da Igreja dos Eremitas de San Girolamo (Segundo Averlino, igual à de Bérgamo).

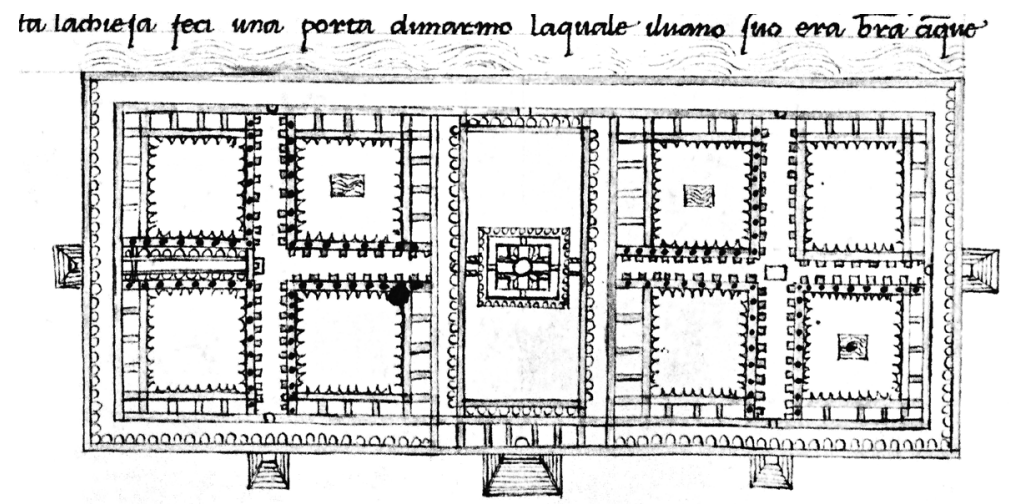

Fig. 3 - FILARETE: Codex Magliabechianus, f 82v. Desenho da planta do hospital de Sforzinda (igual à do Hospital maior em Milão). 

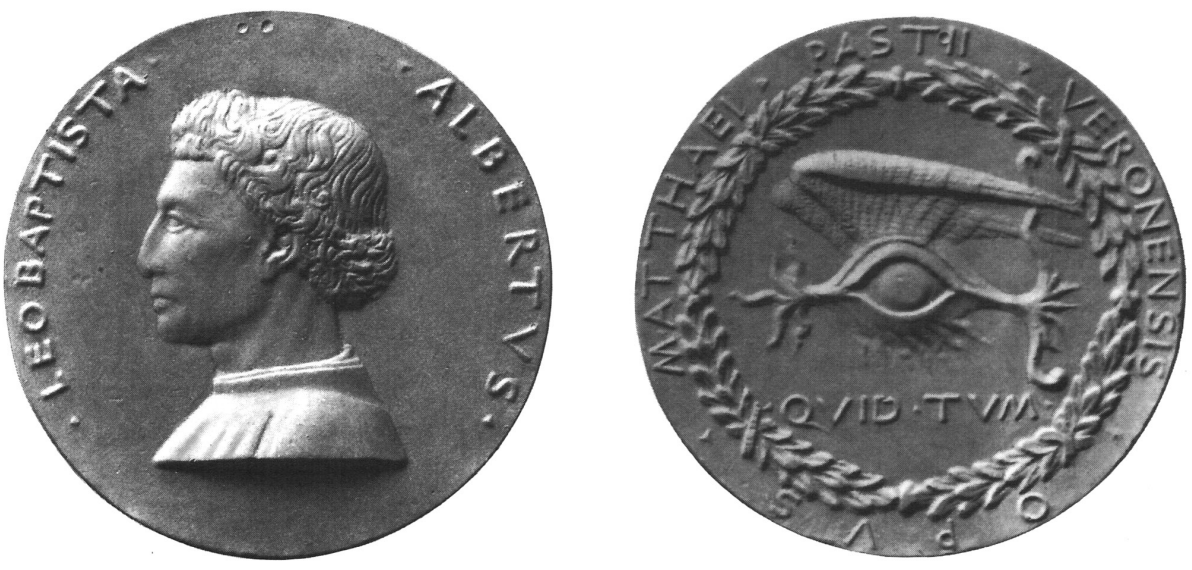

Fig. 4 - MATTEO DE' PASTI: Medalha com busto de Leon Battista Alberti e Olho Alado
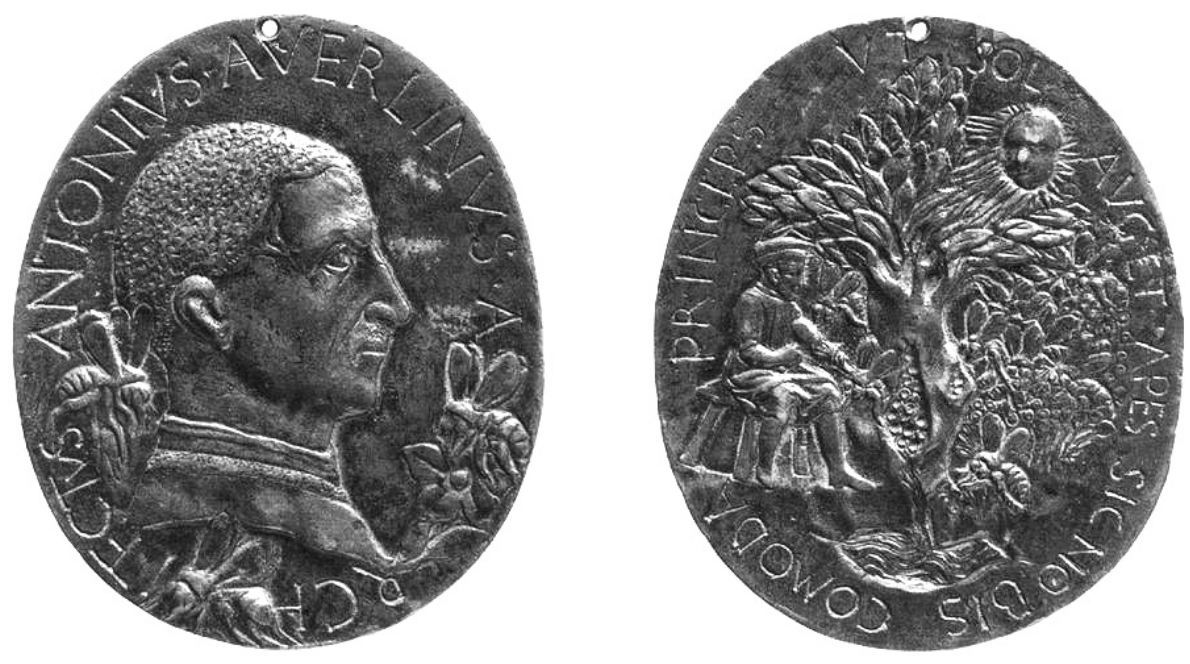

Fig. 5 - FILARETE: Medalha autorretrato 


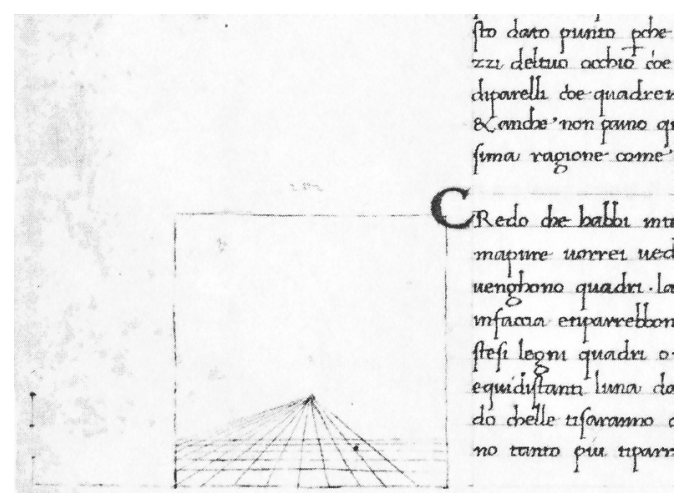

Fig. 6 - FILARETE: Desenho com construção de perspetiva

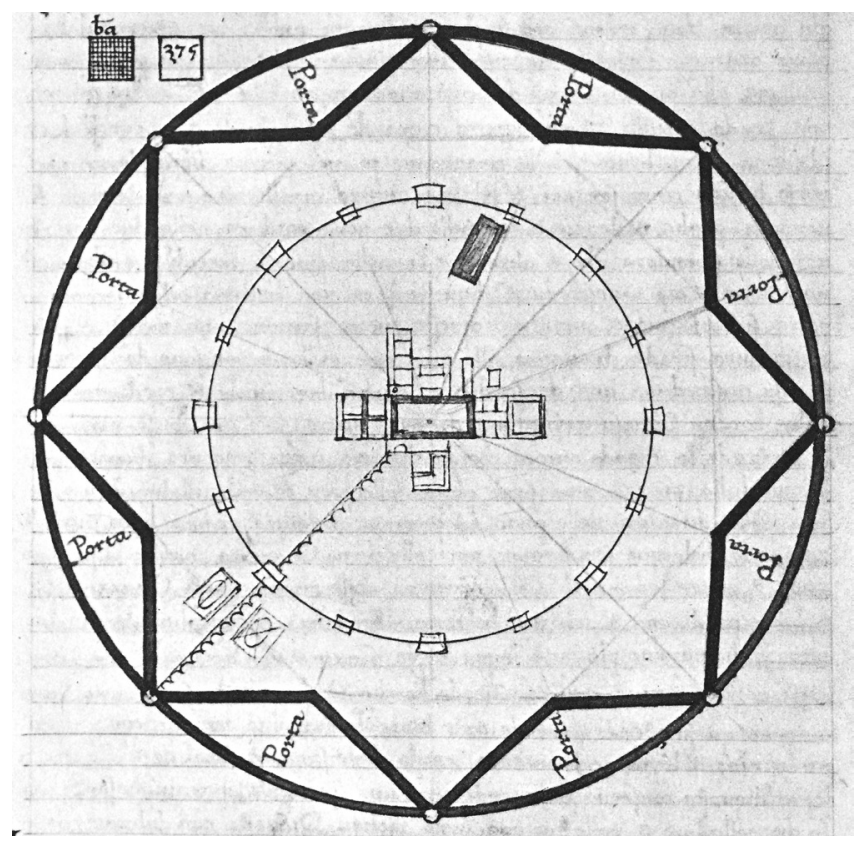

Fig. 7 - FILARETE: Codex Magliabechianus, f. 43r. Desenho com Planta da cidade de Sforzinda. 